Original article

\title{
The effects of emotional intelligence training on anxiety in hemodialysis patients
}

\author{
Fateme Yarahmadi ${ }^{1}$, Seyyede Fateme Ghasemi ${ }^{2 *}$, Said Forooghi ${ }^{3}$
}

(Received: 8 May 2015; Accepted: 17 Oct 2015)

\begin{abstract}
Background and Purpose: Hemodialysis is the most efficient treatment of end-stage renal disease (ESRD), which increases patients' life expectancy. However, it can cause various adverse physical and mental side effects. The aim of this study was to determine the effects of emotional intelligence training on anxiety of hemodialysis patients in Khorramabad, Iran.

Methods: This experimental study was conducted on 74 patients admitted to the hemodialysis ward of Khorramabad hospitals during 2014. The patients were randomized into experimental and control groups. Emotional intelligence training was provided to the experimental group by trained and skilled researchers during two months, within eight sessions. The data collection tools included demographic profile checklist, Spielberger's anxiety questionnaire and emotional quotient inventory (EQ-i), which was filled out by the researcher's assistant throughout the interviews before and after the intervention. The data were analyzed performing covariance analysis, Chi-squared as well as independent and paired t-test, using SPSS 19.

Results: Before the intervention, independent t-test indicated no significant differences in the emotional intelligence scores of the two groups, but after the intervention, this score increased in the experimental group $(\mathrm{P}=0.01)$. The mean state-trait anxiety was not significantly different in the two groups before the intervention. Whereas after the intervention, a significant decrease in the anxiety scores of the experimental group was observed $(\mathrm{P}<0.001)$.

Conclusion: Emotional intelligence training alleviated the anxiety of hemodialysis patients; therefore, implementing emotional intelligence training is recommended for lowering anxiety in hemodialysis patients.
\end{abstract}

Keywords: Anxiety, Emotional intelligence, Hemodialysis

\section{Introduction}

Chronic renal disease is an irreversible progressive loss of glomerular function, which causes uremia and azotemia, and can be treated through hemodialysis and kidney transplantation (1). The number of hemodialysis patients by the year 2020 is estimated to be 3,500,000 (2). In 2012, the association for protection and support of renal patients in Iran announced that there were 75,000 renal patients, 23,000 of whom had been dialyzing. Moreover, the annual growth rate of dialysis patients has been reported to be $15 \%$ (3). Chronic diseases such as severe renal failure are followed by various psychological disorders. The most common symptoms of mental disorders among hemodialysis patients are depression and anxiety, respectively (4). Different studies have reported that the rate of anxiety in hemodialysis patients has increased by $19 \%(5)$.

A study conducted by Ahmadzade and Mehdi demonstrated that the rate of anxiety in patients dialyzing for $1>, 1-2.5$ and $>2.5$ years, were $83.7 \%$, $70 \%$, and $83.3 \%$, respectively (6). Patel et al. have indicated that depression, anxiety as well as suicidal thoughts and tendencies could be found in

\footnotetext{
${ }^{1}$ Student of Critical Care Nursing, Faculty of Nursing and Midwifery, Lorestan University of Medical Sciences, Khorramabad, Iran

2,* Corresponding author: Faculty of Nursing and Midwifery, Lorestan University of Medical Sciences, Khorramabad, Iran. Email: ghasemi2211156@yahoo.com

${ }^{3}$ Faculty of Nursing, Lorestan University of Medical Sciences, Aligoudarz, Iran
} 
hemodialysis patients (7).

So far, various studies have been done to decrease the rate of anxiety in hemodialysis patients using medicinal treatment, continuous care model or orange essence $(8,9)$. To overcome the anxiety in hemodialysis patients, the common methods of treatment such as taking chemical medicines were beyond nurses' responsibilities, and could put the patients' well-being in danger as well; therefore, other remedies should be devised (10).

A study performed by Sunil and Rooprai reflected no significant relationship between emotional intelligence and anxiety reduction in patients (11). While, Franklin et al. demonstrated that high emotional intelligence was accompanied by emotional alignment, which is supportive factor against every day or routine tension and it was a preventive factor in order not to be infected by physical and mental diseases (12). Emotional intelligence is a set of abilities and skills which help individuals to adapt themselves to the environment so as to be successful in their lives (13).

Emotional intelligence can reduce anxiety and increase the level of self-confidence (14). A study carried out by Voshani and Yazdi on female high school students indicated that emotional intelligence training influenced on responding to educational stress, and teaching components of emotional intelligence along with the lessons was effective in decreasing the consequences of educational stress (15). Moreover, Sharif et al. showed that training on emotional intelligence components had major effects on reducing stress among nurses and doctors in intensive care units (16).

The results of a study by Clarke reflected a relationship between emotional intelligence and mental health, while it had a reverse or negative relationship with anxiety (17). Most of the recent studies were done to investigate depression, anxiety and the treatment methods in order to alleviate anxiety, yet none of them has assessed the effect of the emotional intelligence on decreasing anxiety in hemodialysis patients. This study, therefore, was conducted to determine the effect of emotional intelligence training on anxiety of hemodialysis patients during 2014, in Khorramabad, Iran.

\section{Materials and methods}

This experimental study was performed on 74 hemodialysis patients admitted to the dialysis wards of Shohadaye Ashayer and Shahid Rahimi Hospitals during 2014 in Khorramabad, Iran. The participants were randomized into experimental and control groups ( $\mathrm{n}=37$ for each group).

The inclusion criteria were as follow: willing to participate in the study, being in the age range of 1865 years, dialyzing for more than three months, not taking any anti-anxiety medications, not having any verbal or hearing problems and not having dementia or illnesses affecting the brain and memory or lack of ability to think and behave normally.

The exclusion criteria were: lack of willingness to participate in the study, mortality, changing the treatment methods to kidney transplantation or peritoneum dialysis and the emergence of major or severe crisis in patients or their family members. After receiving the approval of Shohadaye Ashayer and Shahid Rahimi Hospitals and Ethics Committee of Lorestan University of Medical Sciences, the aim of the study was explained and informed consent was obtained from the patients before initiating the training intervention.

The data collection tools included demographic profile checklist, Spielberger's anxiety questionnaire and the Baron's emotional intelligence questionnaire. The questionnaires were completed by the researcher's assistant throughout interviews with the patients. The experimental group participated in an eight-week emotional intelligence training program (one session a week). A week after the training program the questionnaires were filled out again.

In order to prevent data collection bias and contact of the samples, the experimental group was separated from the control group with the cooperation of the ward authorities. The Spielberger's State-Trait Anxiety inventory was employed to measure anxiety. This scale contains 40 items, each rated on a 4-point Likert scale ( $1=$ never to $4=$ always). Scores can range from 20 to 80 , with higher scores indicating greater anxiety. For the Persian version of the 
Spielberger's State-Trait Anxiety inventory, Cronbach's Alpha reliability was calculated to be $90 \%$ and $91 \%$ for the state and trait anxiety, respectively (18).

The Persian version of the Emotional Quotient Inventory (Samoui, 2004) which is a 90-item selfreport inventory, was administered to assess the Bar-On model of emotional-social intelligence, which is rated on a 5 -point Likert scale $(1=$ Very seldom or not true of me and 5= Very often true of me). The minimum and maximum possible scores were 90 and 450, respectively.

EQ-i consisted of five composite scales including intrapersonal, general mood, adaptability, interpersonal and stress management. Some items of the questionnaire were scored positively and some others negatively. The questionnaire is consisted of 15 subscales as follows: emotional self-awareness, assertiveness, self-regard, selfactualization, independence, empathy, interpersonal relationship, social responsibility, problem-solving, reality-testing, flexibility, stress tolerance, impulse control, happiness and optimism (19). Cronbach's alpha reliability as well as odd-even mergesort of the scale were calculated to be 0.93 and 0.88 , respectively (20).

The emotional intelligence program which consisted of eight 45-minute sessions, was adapted from the administrative procedures of Bradberry and Greaves (21) and emphasized on the 15 subscales of the BarOn's emotional intelligence model as follows:

To analyze the data, Chi-squared, independent t-test, paired t-test, and covariance analysis were performed, using SPSS 19. The questionnaires were anonymous and the participants' information was collected privately by the researchers.

\section{Results}

The obtained results showed that $58 \%, 2 \%$ and $66 \%$ of our subjects were male, single and married, respectively. The mean age of the samples was $49.7 \pm 10.8$ years, and the mean period of hemodialysis was $3.48 \pm 2.22$ years. Additionally, the results confirmed the hypothesis regarding increasing emotional intelligence scores in the experimental group after implementing the intervention (Table 1).

In this study, most of the subscales including emotional self-awareness, empathy, interpersonal relationships, reality testing, stress tolerance, problem solving, impulse control, optimism and happiness improved significantly by emotional intelligence training.

As can be noted in Table 2, the mean state and trait anxiety scores of the two groups were the same in the intervention group at the pretest stage, while the means were significantly different at the posttest stage.

After the intervention, the state anxiety scores in the hemodialysis patients were significantly different in both groups. The effects of pretest (participants' scores of the state anxiety test before the intervention) were controlled using covariance analysis, which proposes some assumptions such as homogeneity of regression slopes within the random variable (pretest) and the dependent variable (participants' scores of the state anxiety test after the intervention) in both groups.

Variance analysis was conducted, which rejected the interaction between the independent variable (group effect) and the covariate variable (the scores of the state anxiety before the intervention);

\begin{tabular}{ll}
\hline Session & Topic \\
\hline 1 & Introducing and building relationship with patients \\
\hline 2 & Defining emotion (excitement) and identifying its sorts in our lives and recognizing facial expressions, thoughts, embedded emotions and excitements \\
\hline 3 & Investigating the automatic thoughts, excitements, and behaviors through scientific samples \\
\hline 4 & Identifying how excitement happen to others \\
\hline 6 & Expressing excitement in different ways and how to handle them in our lives \\
\hline 7 & Excitement management (one) ( prediction of excitements and understanding its first signs in ourselves) \\
\hline 8 & $\begin{array}{l}\text { Excitement management (two) (controlling excitement through changing position, calming and emotional keywords) } \\
\text { stress, solve problems and be optimistic) }\end{array}$ \\
\hline
\end{tabular}


Table 1. The mean emotional intelligence scores of the control and experimental groups before and after the training intervention

\begin{tabular}{|c|c|c|c|c|c|}
\hline $\begin{array}{l}\text { Emotional } \\
\text { intelligence }\end{array}$ & $\begin{array}{l}\text { The control } \\
\text { group } \\
\text { SD } \pm \text { Mean }\end{array}$ & $\begin{array}{c}\text { The } \\
\text { experimental } \\
\text { group } \\
\text { SD } \pm \text { Mean }\end{array}$ & $t^{*}$ & df & Sig. \\
\hline before & $297.73 \pm 16.17$ & $295.08 \pm 16 / 18$ & .65 & 72 & .516 \\
\hline after & $\begin{array}{r}298 / 05 \\
\pm 10 / 66\end{array}$ & $\begin{array}{l}304 / 89 \\
\pm 15 / 06\end{array}$ & -2.23 & 70 & .029 \\
\hline$t^{* *}$ & .09 & $-2 / 74$ & - & - & - \\
\hline$d f$ & 36 & 36 & - & - & - \\
\hline Sig. & .92 & .01 & - & - & - \\
\hline
\end{tabular}

consequently, there was a criterion for regression homogeneity.

Also regarding the significance level of the Levene's test $(\mathrm{F}=0.052, \mathrm{df}=72$ and $\mathrm{P}=0.819)$, the data didn't impair the validity of the assumption of equality of variance error; therefore, the samples met the criterion for the homogeneity of variances (Tables 3).

After modifying the scores of the pretest, there was a significant $\mathrm{F}$ between the group scores, that is $\mathrm{F}=39.57$ and $\mathrm{P}<0.001$.

It can be inferred from the modified mean scores of state anxiety (the mean of the experimental group was 42.79 and the mean of the control group was 49.15 ) that the anxiety scores decreased significantly in the experimental group. The results demonstrated the group effect (the intervention effect), with deleting the covariant variable, was also statistically significant. Therefore, independent variable was significantly different in the two groups, which could be as a result of emotional intelligence. Furthermore, this effect size i.e., 0.358, in other words, $36 \%$ of the overt anxiety reduction, was associated with the influence of the pretest variable.

Table 3. The results of variance analysis of state anxiety for the control and experimental groups

\begin{tabular}{lcccccc}
\hline $\begin{array}{l}\text { The effect } \\
\text { sources }\end{array}$ & $\boldsymbol{\Sigma}_{\mathbf{x}}{ }^{2}$ & df & $\begin{array}{c}\text { Mean } \\
\mathbf{X}^{2} \text { of }\end{array}$ & F & Sig. & $\begin{array}{c}\text { Eta } \\
\text { Coefficient }\end{array}$ \\
\hline Pretest & $* 6800.34$ & 1 & 6800.34 & 360.80 & .000 & .83 \\
\hline Group & 745.73 & 1 & 745.73 & 39.56 & .000 & .35 \\
\hline Error & 1338.19 & 71 & 18.84 & - & & \\
\hline Total & 165090.00 & 74 & - & - & & \\
\hline *.R Squared $=.846$ & (Adjusted R Squared=.842) &
\end{tabular}

Table 2. State and trait anxiety mean scores of the experimental and control groups

\begin{tabular}{lccc}
\hline Variables & The Groups & Mean & SD \\
\hline \multirow{2}{*}{ The pretest of state anxiety } & Experimental & 50.56 & $75 / 11$ \\
\cline { 2 - 4 } & Control & 59.49 & $18 / 9$ \\
\hline \multirow{2}{*}{ The posttest of state anxiety } & Experimental & $24 / 43$ & $23 / 11$ \\
\cline { 2 - 4 } & Control & $70 / 48$ & $99 / 9$ \\
\hline \multirow{2}{*}{ The pretest of trait anxiety } & Experimental & $02 / 50$ & $99 / 11$ \\
\cline { 2 - 4 } & Control & $45 / 48$ & $13 / 11$ \\
\hline \multirow{2}{*}{ The posttest of trait anxiety } & Experimental & $16 / 42$ & $66 / 11$ \\
\cline { 2 - 4 } & Control & $08 / 48$ & $11 / 11$ \\
\hline
\end{tabular}

Mean trait anxiety score in the hemodialysis patients was significantly different after the intervention for both groups. The effects of pretest (participants' scores of the trait anxiety test before the intervention) were controlled using covariance analysis, which proposes some assumptions such as homogeneity of regression slopes within the random variable (pretest) and the dependent variable (participants' scores of the trait anxiety test after the intervention) in both groups.

Variance analysis was conducted and regarding the $\mathrm{P}$-value (i.e., $\mathrm{P}=0.541$ ), the interaction between the independent variable (group effect) and the covariate variable (the scores of the trait anxiety before the intervention) was rejected; consequently, there was a criterion for regression homogeneity.

Regarding the significant level of the Levene's test $(\mathrm{F}=0.338, \mathrm{df}=72$ and $\mathrm{P}=0.563)$, the data didn't impair the assumption of equality of the variance error; therefore, the samples met the criterion for the homogeneity of variances (Table 4).

After modifying the pretest scores, there was a significant $\mathrm{F}$ between the group scores, that is $\mathrm{F}=92.097$ and $\mathrm{P}<0.001$.

It can be inferred from the modified mean scores of trait anxiety (the experimental group's

Table 4. The results of variance analysis of trait anxiety for the control and experimental groups

\begin{tabular}{lcccccc}
\hline $\begin{array}{l}\text { The effect } \\
\text { sources }\end{array}$ & $\boldsymbol{\Sigma}_{\mathbf{x}}{ }^{2}$ & $\boldsymbol{d f}$ & $\begin{array}{c}\text { Mean } \\
\text { of } \mathbf{X}^{2}\end{array}$ & $\mathbf{F}$ & Sig. & $\begin{array}{c}\text { Eta } \\
\text { Coefficient }\end{array}$ \\
\hline Pretest & 7976.10 & 1 & 7976.10 & 473.19 & .000 & 0.87 \\
\hline Group & 1552.36 & 1 & 1552.36 & 92.09 & .000 & 0.56 \\
\hline Error & 1196.75 & 71 & 16.85 & - & & \\
\hline Total & 154873.00 & 74 & - & - & & \\
\hline
\end{tabular}

*. a. R Squared $=0.884$ (Adjusted R Squared $=0.880$ ) 
mean score $=39.61$ and the control group's mean score $=48.79$ ) that the anxiety level in the experimental group diminished more significantly, as compared to the control group. The results demonstrated that the group effect or the intervention effect, with deleting the covariant variable, was also statistically significant. Thus, it can be concluded that the emotional intelligence training made a difference in the level of the independent variable in the two groups. Furthermore, this effect size, i.e., 0.565 or in other words, $56 \%$ of trait anxiety reduction, was due to the influence of the pretest variable.

\section{Discussion}

All hemodialysis patients have experienced anxiety to some extent. In this study, the mean state and trait anxiety scores were 50.56 and 50.02 , respectively. The rate of anxiety in patients dialyzing for $1>, 1-2.5$ and $>2.5$ years were $83.8 \%$, $70 \%$ and $83.3 \%$, respectively (6). Kanani et al. have indicated that the mean score of state anxiety was 46.9 for experimental group and 48.3 for control group before the intervention. This result indicated that the level of anxiety in hemodialysis patients is higher (9). Several studies have suggested that the hemodialysis patients were at high risk for depression and anxiety, and approximately $20 \%$ of hemodialysis patients had anxiety (22).

The results of this study demonstrated that there was a significant negative relationship between emotional intelligence and patients' anxiety. The state and trait anxiety scores significantly decreased among those who received the training program on emotional intelligence. Quite in line with our results, Sharif et al. indicated that the mean state anxiety score of doctors and nurses was 46.59 before receiving training on emotional intelligence, while after the training program, it decreased to 39.95. Moreover, mean trait anxiety score before the intervention was 40.03 , whereas after the program it declined to 36.23 (16).

In a study by Voshani and Yazdi, it was suggested that providing training on emotional intelligence and reacting to educational stress significantly decreased the anxiety scores of high school students
$(\mathrm{P}<0.001)$ (15). Additionally, in a study by Sunil and Rooprai, it was concluded that there is a significant negative relationship between emotional intelligence and anxiety (11). In another study performed on university students to determine the relationship between emotional intelligence components (subscales) and the anxiety symptoms, it was found that components of excitement, clarity and temperamental alteration could predict the anxiety symptoms. This study showed that emotional intelligence had a significant negative relationship with the symptoms of anxiety $(\mathrm{P}<0.001)$ (23). Martins et al. in review article accentuated the fact that emotional intelligence is mostly associated with mental health rather than physical health (24).

Hemodialysis patients, due to various physiological changes, experience mental tension so that most of them suffer from anxiety. Anxiety in dialyzing patients leads to dependence on others, social isolation, low quality of life, behavioral problems, anger, uncooperativeness, distorted mental images, stress, feeling inefficient, trouble in social relationships, lack of sympathy, trouble in intrapersonal communication, impaired problemsolving abilities, lack of happiness and so forth.

As anxiety diminishes, life quality, satisfaction, exultation, stress tolerance, sleep quality and social relationships improves in hemodialysis patients. The findings of the present study indicated that providing emotional intelligence training improved the subscales of emotional intelligence which in turn, lowered anxiety in the hemodialysis patients of the experimental group.

In contract to a study by Nouriyan (16), where all the subscales of emotional intelligence increased, in this study, our study most of the subscales improved significantly by the training program. The reason for this discrepancy might be the short duration of the training course or the demographics of the subjects (e.g., age and education). Despite the fact that emotional intelligence training at lower ages might render better results, providing emotional intelligence training later in life can also be effective although it might take longer. Therefore, geriatric patients are suggested to attend longer emotional intelligence training programs. 


\section{Conclusion}

The results of this study demonstrated that emotional intelligence training lowers anxiety in hemodialysis patients. Considering the effectiveness of the emotional intelligence training, this program can be implemented as a workshop for dialysis nurses or can be provided in dialysis wards utilizing audiovisual equipment.

\section{Conflict of interest}

This article has been derived from an MSc thesis, supported by Lorestan University of Medical Sciences.

\section{Authors' contributions}

All the authors contributed equally in this study.

\section{Acknowledgements}

This article has been derived from an MSc thesis. We would like to thank the assistant of deputy of research and technology of Lorestan University of Medical Sciences for approving the plan with 1840 codes and his financial support. Our special thanks go to all the staff and patients of dialysis wards of Shohadaye Ashayer and Shahid Rahimi Hospitals in Khorramabad. Also, our heartfelt thanks are due to all the professors who cooperated with this study.

\section{Refrences}

1. Zamanzadeh V, Heidarzadeh M, Oshvandi Kh, Lakdizaji S. Relationship between quality of life and social support in hemodialysis patient in Imam Khomeini and Sina Educational Hospitals of Tabriz. J Tabriz Univ Med Sci 2007; 29(1):49-54 (Persian).

2. Davids MR. Chronic Kidney disease-the silent epidemic. CME 2007; 25(8): 378-82.

3. Statistics Dialysis Patients Increased by $15 \%$ Annually [Internet] 2012. Available from: http//khabarfarsi.com/ ext/3210584.2012/8/19

4. Navidian A, Arbabi Sarjou A, Kikhai A. Frequency of mental disturbances in hemodialysis patients referred hemodialysis ward of Khatam-Al-Anbia Hospital in Zahedan. J Gilan Univ Med Sci 2006; 58(15):61-70 (Persian).

5. Cukor D, Coplan J, Brown C, Friedman S, CromwellSmith A, Peterson RA, et al. Depression and anxiety in urban hemodialysis patients. Clin J Am Soc Nephrol 2007; 2(3):484-90.

6. Ahmadzadeh GH, Mehdi M. The Prevalence of Depression, Anxiety and Psychosis among Hemodialysis patients in Nour and Ali Asghar Hospitals in Isfahan. J Isfahan Med School 2012; 29(162):1918-26.

7. Patel ML, Sachan R, Nischal A, Surendra. Anxiety and depression - a suicidal risk in patients with chronik renal failure on maintenance hemodialysis. Inter J Sci Res Pub 2012; 2(3):1-6

8. Rahimi A, Ahmadi F, Gholiaf M. Effects of applying continuous care model (CCM) on stress, anxiety and depression in hemodialysis patients. Res Med J 2006; 30(4):361-9.

9. Kanani M, Mazloum SR, Emami A, Mokhber N. The effect of aromatherapy with orange essential oils on anxiety in patients undergoing hemodialysis. J Sabzevar Univ Med Sci 2012; 19(3):249-57

10. 10. Imanishi J, Kuriyama H, Shigemori I, Watanabe S, Aihara Y, Kita M, et al. Anxiolytic effect of aromatherapy massage in patients with breast cancer. Evid Based Complement Alternat Med 2009; 6(1):123-8.

11. Sunil K, Rooprai KY. Role of emotional intelligence in managing stress and anxiety at workplace. Proceeding of the ASBBS Annual Conference; 2009; Las Vegas, USA.

12. Marino BS, Cassedy AE, Drotar D, Wernovsky G, Franklin R, Brown K, et al. Psychosocial morbidity factors mediate the relationship between heart disease complexity and lower quality of life. J Am Coll Cardiol 2012; 59(13s1):E773.

13. Bar-On R, Brown JM, Kirkcaldy BD, Thome EP. The Emotional Quotient Inventory (EQ-I): A Measure of Emotional Intelligence. 2nd ed. Toronto, Canada; MultiHealth System Inc.

14. Boussiakou LG, Boussiakou IK, Kalkani EC. Student development using emotional intelligence. Word Trans Eng Tech Edu 2006; 5(1):53-8.

15. Emami Moghaddam Z, Davoudi M, Behnam Voshani HR, Amin Yazdi SA. The effect of teaching emotional intelligence skills on response to educational stress in high school girls. EBCJ 2013; 3(5):27-36 (Persian).

16. Nooryan Kh, Gasparyan Kh, Sharif F, Zoladl M, Moghimi M, Hosseini NA. The effects of Emotional intelligence items education on job related stress in physicians and 
nurses who work in intensive care units. ArmaghaneDanesh 2011; 16(5):472-9 (Persian).

17. Clarke N. The impact of a training programme designed to target the emotional intelligence abilities of project managers. Inter J Pro Manag 2010; 28(5):461-80.

18. Mahram B. Spielbergers state trait anxiety questionnaire [Doctoral Dissertation]. Mashhad: Faculty of Psychology, Ferdowsi University of Mashhad; 1993 (Persian).

19. Bar-On R. The emotional Quotient Inventory (EQ-i): A Test of Emotional Intelligence. Canada: Multi-Health Systems Inc; 1997.

20. Samoui R. Normalization of baron emotional quotient questionnaire. Tehran: Sina psychological institute publication; 2004. p.113 (Persian).
21. radberry T, Greaves J. The emotional intelligence quick book [M. Ganji, H. Ganji, trans]. Tehran: Savalan Publishing; 2003. P.17-28.

22. Cukor D, Coplan J, Brown C, Peterson RA, Kimmel PL. Course of depression and anxiety diagnosis in patients treated with hemodialysis: a 16- month Follow-up. Clin J Am Soc Nephrol 2008; 3(6):1752-8.

23. Mashhadi A, Soltani Shurbakhorloo E, Hashemi Razini S. On the relationship between emotional intelligence and its components of with symptoms of anxiety. J Fund Mental Health 2011; 12(4):652-61 (Persian).

24. Martins A, Ramalho N, Morin E. A comprehensive metaanalysis of the relationship between Emotional intelligence and health. Pers Individ Dif J 2010; 49(6):554-64. 